\title{
Improvement of laccase production by Pleurotus ostreatus by means of agroindustrial waste and fermentation kinetics
}

\author{
Zhao LH*, Chen W, Wang LL, Sun HJ and Zhu Z \\ School of Civil and Architectural Engineering, Liaoning University of Technology, Jinzhou 121001, China
}

Zhao LH*, Chen W, Wang LL, Sun HJ, Zhu Z 2017 - Improvement of laccase production by Pleurotus ostreatus by means of agroindustrial waste and fermentation kinetics. Mycosphere 8(1), 147-161, Doi 10.5943/mycosphere/8/1/14

\begin{abstract}
The main challenges faced by laccase production are high cost and low laccase activity. In this work, optimization of laccase production was studied by addition of agroindustrial waste, and enzyme fermentation kinetics were analyzed to determine the reasons for the resulting enhancement of laccase production. The results revealed that among various types of agroindustrial waste, orange peel is the best inducer of laccase. The maximal laccase activity of cultures containing orange peel was 9-fold higher than that of cultures without any agroindustrial waste, and the fermentation duration was reduced from 12 to 8 days. A kinetic model of fermentation was devised, and the effects of agroindustrial waste, copper induction, and the agitation rate on fermentation kinetics were analyzed. The reasons for improvement of laccase production by copper and by regulating the rotation speed include improved characteristics of laccase-producing fungi and enhanced proliferation capacity, respectively.
\end{abstract}

Key words - kinetic model - laccase - optimization - white rot fungi

\section{Introduction}

Laccases (p-diphenol:oxygen oxidoreductases [EC1.10.3.2]) are multicopper enzymes that catalyze oxidation of a variety of phenolic and aniline compounds with the concomitant reduction of molecular oxygen to water (Unal et al. 2011, Asadgol et al. 2014). Laccase has broad-spectrum activity, high efficiency, and low consumption, and can use the oxidant $\mathrm{O}_{2}$ directly without any coenzyme factors (Baldrian 2006). Consequently, laccase has been widely used in industries such as pulping, waste water treatment, degradation of lignin and xenobiotic materials, dye decolorizing, and restoration of food industry wastewater (Baldrian 2006, Zhang et al. 2014, Mohajershojaei et al. 2015, Sondhi et al. 2015). 
Laccase producers include plants, animals, fungi, and bacteria, but most laccase comes from white-rot fungi (Singh Arora \& Kumar Sharma 2010, Chairin et al. 2013, Sathishkumar et al. 2013, Li et al. 2014). Nevertheless, there have been some common problems including low laccase activity and high production cost, which hamper large-scale production (Minussi et al. 2007, Tinoco-Valencia et al. 2014). Attempts have been made to use agroindustrial waste to generate several value-added products, including enzymes, because the use of agroindustrial waste can reduce enzyme production cost while generating higher concentrations of products (Akpinar \& Urek 2014, Gassara et al. 2011). Similarly, a recent approach was shown to solve serious environmental problems caused by large amounts of agroindustrial waste (Vendruscolo et al. 2008, Mussatto 2009). Reddy et al. (2003) studied the ability of two Pleurotus species to produce lignolytic and cellulolytic enzymes and found that the production of such enzymes by two Pleurotus species ( $P$. ostreatus and $P$. sajor-caju) is cheaper when banana waste is used. Seyis and Aksoz (2005) concluded that the use of some types of agroindustrial waste (orange peel, lemon pomace, banana peel, and hazelnut shell) in the production of xylanase may decrease the cost in an environmentally sound manner.

Pleurotus ostreatus is a species of white-rot fungi that produces extracellular enzymes including laccase and manganese peroxidase but no lignin peroxidase (Giardina et al. 2000). In the present study, laccase production by $P$. ostreatus was improved by adding agroindustrial waste such as orange peel, sugarcane bagasse, corn stalk, tea, and peanut shells. Fermentation kinetics were studied: kinetic models were devised and effects of agroindustrial waste, copper induction, and agitation on the fermentation kinetics were analyzed. The main objectives of this work were to find the optimal agroindustrial waste for the production of laccase by $P$. ostreatus and to identify the reasons for the enhancement of laccase production from the perspective of fermentation kinetics. Furthermore, another aim was to better understand the laccase fermentation process and provide theoretical and technical basis for industrial production of this enzyme.

\section{Materials \& Methods}

\section{Fungal strains, culture media, and agroindustrial substrates}

White-rot fungus $P$. ostreatus was obtained from the microbiology laboratory at the School of Civil and Architectural Engineering, Liaoning University of Technology, Jinzhou, China. For routine experiments, the white-rot fungus was maintained on a $2 \%$ agar slant of the following composition: glucose $20.0 \mathrm{~g} / \mathrm{L}$, potato extract $200 \mathrm{~g} / \mathrm{L}$, and agar $20 \mathrm{~g} / \mathrm{L}$. Prior to sterilization, $\mathrm{pH}$ of the agar medium was adjusted to 6.5 with diluted hydrochloric acid. The agar plates were incubated at $28^{\circ} \mathrm{C}$ for 7 days.

Various types of agroindustrial wastes were obtained from a local market in Jinzhou. The substrates were treated with a $0.5 \% \mathrm{v} / \mathrm{v}$ hypochlorite solution for $5 \mathrm{~h}$. After that, they were rinsed with distilled water until $\mathrm{pH}$ became neutral. Finally, they were oven dried at $60^{\circ} \mathrm{C}$ until constant weight. They were then crushed to an average particle size of $\sim 0.8 \times 0.5 \mathrm{~mm}$ before addition to a liquid medium (Gonzalez et al. 2013).

\section{Culture conditions}

Different substrates ( $1.5 \mathrm{~g}$; tea, peanut shells, orange peel, corn cob, and bagasse) were added to a 300-ml Erlenmeyer flask containing $150 \mathrm{ml}$ of the basal liquid medium. This medium (used for laccase production) consisted of glucose $(20.0 \mathrm{~g} / \mathrm{L}),\left(\mathrm{NH}_{4}\right)_{2} \mathrm{SO}_{4}(0.5 \mathrm{~g} / \mathrm{L}), \mathrm{KH}_{2} \mathrm{PO}_{4}(2 \mathrm{~g} / \mathrm{L})$, $\mathrm{MgSO}_{4} \cdot 7 \mathrm{H}_{2} \mathrm{O}(0.5 \mathrm{~g} / \mathrm{L})$, and $\mathrm{VB}_{1}(0.02 \mathrm{~g} / \mathrm{L}) ; \mathrm{pH}$ of the liquid medium was adjusted to 6.5 with diluted hydrochloric acid before sterilization by autoclaving. Mycelia and spore suspensions of stock 
cultures were used as the inoculum source. An inoculant of $1.5 \mathrm{ml}$ was prepared by resuspending the stock culture. The flasks were incubated at $30^{\circ} \mathrm{C}$ in an incubator shaker rotating at $150 \mathrm{rpm}$ for up to 12 days. The culture liquids of submerged cultures were separated from the mycelia or substrates by centrifugation at $8500 \mathrm{rpm}$.

The amount of orange peel ranged from 0 to $3.0 \mathrm{~g}(0,0.75,1.5$, or $3.0 \mathrm{~g})$, and $\mathrm{CuSO}_{4}$ was added at different concentrations $(0,0.1,1.0$, or $2.0 \mathrm{mM})$ to the basal medium on the third day of incubation. The effects of the agitation rate on fermentation kinetics were evaluated by varying the rotation speed from 100 to $250 \mathrm{rpm}(100,150,200$, and $250 \mathrm{rpm})$ without adding substrates or $\mathrm{CuSO}_{4}$. All cultures were incubated at $30^{\circ} \mathrm{C}$ in an incubator shaker for up to 12 days.

\section{Analytical measurements}

Concentration of the fungi was determined by the dry weight of fungal mycelium (Tavares et al. 2005). To easily determine the dry weight of the orange peel extract, the orange peel was replaced with orange peel extract. The orange peel extract was prepared as follows: a certain quantity $(0.75$, $1.5,3.0 \mathrm{~g}$ ) of orange peel was added to a 300-ml Erlenmeyer flask containing $150 \mathrm{ml}$ of the basal liquid medium, and the flasks were placed into the autoclave for $25 \mathrm{~min}$ at $125^{\circ} \mathrm{C}$. The orange peel was eliminated by filtration in a sterile environment.

Laccase activity was measured using 2,2'-azino-bis (3-ethylbenzothiazoline-6-sulfonic acid) (ABTS) as a substrate at $35^{\circ} \mathrm{C}$. ABTS $(1 \mathrm{ml}$ of a $0.5 \mathrm{mM}$ solution) was mixed with $1 \mathrm{ml}$ of a $0.1 \mathrm{M}$ acetic acid/sodium acetate buffer solution $(\mathrm{pH} 4.0)$ and $1 \mathrm{ml}$ of diluted crude enzyme. Oxidation of ABTS was monitored by the increasing absorbance at $420 \mathrm{~nm}(\varepsilon=36000 /[\mathrm{M} \cdot \mathrm{cm}])$ in $5 \mathrm{~min}$. One unit of the enzymatic activity was defined as the amount of the enzyme that oxidizes $1 \mu \mathrm{mol}$ of ABTS per minute (Elisashvili et al. 2008). The concentration of glucose was measured by means of 3,5-dinitrosalicylic acid (DNS) (Miller 1959).

\section{Kinetic modeling}

Kinetic experiments with biological fermentation were focused on three parameters: cell growth $(\mathrm{X})$, product formation $(\mathrm{E})$, and substrate consumption $(\mathrm{G})$. Usually, they are expressed by the Logistic equation (Eq), Luedeking-Piret equation, and the Luedeking-Piret-like equation, respectively (Elibol \& Mavituna 1999, Tavares et al. 2005, Bankar \& Singhal 2012, Bettin et al. 2014, Saat et al. 2014).

\section{The model of microbial growth}

The microbial growth model can be described as follows (Elibol \& Mavituna 1999):

$$
\ln \frac{x}{\left(x_{\max }-x\right)}=\mu_{\mathrm{m}} t-\ln \left(\frac{x_{\max }}{x_{0}}-1\right)
$$

The value of $\mathrm{x}_{\max }$ was obtained from experimental data. A line was drawn with $\ln \left[x /\left(x_{\max }-x\right)\right]$ as the ordinate and $t$ (fermentation time) as the abscissa. The value of the slope and the vertical intercept are equal to $\mu_{\mathrm{m}}$ and $-\ln \left(x_{\max } / x_{0}-1\right)$. Furthermore, $\mu_{\mathrm{m}}$ and $\mathrm{x}_{0}$ can be determined according to $\mathrm{x}$ and $\mathrm{x}_{\max }$, and the fungal growth model can thus be constructed.

The initial biomass concentration $\left(\mathrm{x}_{0}\right)$ played a vital role in increasing the total biomass production. The rate of biomass production is determined by the characteristics of fungal growth and population size. The specific growth rate $(\mu)$ depends only on fungal characteristics and 
environmental factors and has nothing to do with population size. The specific growth rate $(\mu)$ can be defined as the proliferation capacity of the fungi. Assuming that the fungi reproduce strictly by binary fission, when $\mathrm{x}_{\mathrm{t}}$ reaches $2 \mathrm{x}_{0}$, the required time is called the generation time (GT). The greater the $\mu$, the less is GT.

$$
G T=\frac{\ln 2}{\mu}=\frac{0.693}{\mu}
$$

\section{Model of laccase formation}

The basis of the kinetics of product formation is expressed by the Luedeking-Piret equation. For the first time, this model was used for the production of lactic acid by Lactobacillus delbrueckii.

$$
\frac{d E}{d t}=\alpha\left(\frac{d x}{d t}\right)+\beta x
$$

where $\mathrm{dE} / \mathrm{dt}$ is the rate of laccase production $(\mathrm{U} /[\mathrm{mL} \cdot \mathrm{d}]), \alpha$ is a growth-associated constant $(\mathrm{U} / \mathrm{g})$, and $\beta$ is a biomass-associated constant $(\mathrm{U} /[\mathrm{g} \cdot \mathrm{d}])$. Equation (3) can be changed as

$$
d E=\alpha(d x)+\beta x(d t)
$$

Integration of Eq. (4) produces the following equation:

$$
\begin{aligned}
& \int_{n}^{n+1} d E=\alpha\left(x_{n+1}-x_{n}\right)+\beta \int_{n}^{n+1} x d t \\
& E_{\mathrm{n}+1}-E_{\mathrm{n}}=\alpha\left(x_{\mathrm{n}+1}-x_{\mathrm{n}}\right)+\beta \int_{n}^{n+1} x d t
\end{aligned}
$$

Assuming that the error of Eq. (6a) can be neglected,

$$
\begin{aligned}
& \int_{n}^{n+1} x d t=\frac{\left(x_{\mathrm{n}+1}+x_{\mathrm{n}}\right)}{2}=x_{\mathrm{n}+\frac{1}{2}} \\
& E_{\mathrm{n}+1}-E_{\mathrm{n}}=\alpha\left(x_{\mathrm{n}+1}-x_{\mathrm{n}}\right)+\beta x_{\mathrm{n}+\frac{1}{2}}
\end{aligned}
$$

Because $\alpha$ and $\beta$ are constant under certain culture conditions. Now $\alpha$ can be considered the laccase production or destruction coefficient of the fungi at a small fungal age $(\mathrm{U} / \mathrm{g})$, and $\beta$ is the laccase production coefficient of the fungi at older fungal age $(\mathrm{U} /[\mathrm{g} \cdot \mathrm{d}])$. The values of $\alpha$ and $\beta$ depend on the fermentation conditions.

When $\mathrm{dx} / \mathrm{dt}=0$ and $\mathrm{x}=\mathrm{x}_{\max }, \beta$ can be obtained by means of Eq. (3):

$\beta=\frac{d E / d t}{x_{\max }}$

A combination of Eqs. (1) and (3) produces the following relation:

$$
\frac{d E}{d t}=\alpha\left\{\mu_{\mathrm{m}} x\left(1-\frac{x}{x_{\max }}\right)\right\}+\beta \frac{x_{0} \exp \left(\mu_{\mathrm{m}} t\right)}{\left\{1-\left(x_{0} / x_{\max }\right)\left(1-\exp \left(\mu_{\mathrm{m}} t\right)\right)\right\}}
$$

The integrated form of Eq. (3) is the following:

$$
E-E_{0}=\alpha x_{0}\left\{\frac{\exp \left(\mu_{\mathrm{m}} t\right)}{1-\left(x_{0} / x_{\max }\right)\left(1-\exp \left(\mu_{\mathrm{m}} t\right)\right)}-1\right\}+\beta \frac{x_{\max }}{\mu_{\mathrm{m}}} \ln \left\{1-\frac{x_{0}}{x_{\max }}\left(1-\exp \left(\mu_{\mathrm{m}} t\right)\right)\right\}
$$

$\mathrm{E}_{0}=0$, Eq. (9) can be transformed to the following equations:

$$
E=\alpha A(t)+\beta B(t)
$$




$$
A(t)=x_{0}\left\{\frac{\exp \left(\mu_{\mathrm{m}} t\right)}{1-\left(x_{0} / x_{\max }\right)\left(1-\exp \left(\mu_{\mathrm{m}} t\right)\right)}-1\right\} ; B(t)=\frac{x_{\text {max }}}{\mu_{\mathrm{m}}} \ln \left\{1-\frac{x_{0}}{x_{\max }}\left(1-\exp \left(\mu_{\mathrm{m}} t\right)\right)\right\}
$$

A plot of $E-\beta B(t)$ versus time (t) will give a line of the slope $\alpha$.

\section{The model of glucose consumption}

Glucose was mainly used for biomass growth, product formation, and for maintaining cell metabolism. The model of glucose consumption was based on the Luedeking-Piret-like equation:

$$
-\frac{d G}{d t}=\frac{1}{Y_{\mathrm{x} / \mathrm{G}}} \frac{d x}{d t}+\frac{1}{Y_{\mathrm{E} / \mathrm{G}}} \frac{d E}{d t}+m_{\mathrm{s}} x
$$

Where $\mathrm{dG} / \mathrm{dt}$ is the rate of glucose consumption $(\mathrm{U} /[\mathrm{g} \cdot \mathrm{d}]), \mathrm{G}_{0}$ is the initial glucose concentration $(\mathrm{g} / \mathrm{L}), \mathrm{G}$ is the glucose concentration $(\mathrm{g} / \mathrm{L}), \mathrm{Y}_{\mathrm{X} / \mathrm{G}}$ is the biomass yield coefficient on glucose $(\mathrm{g} / \mathrm{g})$, $\mathrm{Y}_{\mathrm{E} / \mathrm{G}}$ is the laccase activity yield coefficient on glucose $(\mathrm{g} / \mathrm{g})$, and $\mathrm{m}_{\mathrm{s}}$ is the fungal maintenance coefficient on glucose $(\mathrm{g} / \mathrm{g} / \mathrm{d})$.

Assuming that the amount of glucose used for laccase formation is negligible, Eq. (11) can be reduced to the following equation.

$$
-\frac{d G}{d t}=\frac{1}{Y_{\mathrm{x} / \mathrm{G}}} \frac{d x}{d t}+m_{\mathrm{s}} x=\eta \frac{d x}{d t}+\theta x
$$

Just as the laccase formation model, the glucose consumption model can be understood by the method described above. When $\mathrm{dx} / \mathrm{dt}=0, \mathrm{x}=\mathrm{x}_{\max }$, and $\theta$ can be obtained by Eq. (13).

$$
\theta=-\frac{d G / d t}{x_{\max }}
$$

Integrating Eq. (12)

$$
\begin{aligned}
& G=G_{0}-\eta x_{0}\left\{\frac{\exp \left(\mu_{\mathrm{m}} t\right)}{1-\left(x_{0} / x_{\max }\right)\left(1-\exp \left(\mu_{\mathrm{m}} t\right)\right)}-1\right\}-\theta \frac{x_{\max }}{\mu_{\mathrm{m}}} \ln \left\{1-\frac{x_{0}}{x_{\max }}\left(1-\exp \left(\mu_{\mathrm{m}} t\right)\right)\right\} \\
& G=G_{0}-\eta A(t)-\theta B(t)
\end{aligned}
$$

Plotting $G_{0}-\theta B(t)-G$ versus $A(t)$ will yield a straight line passing through the origin. The slope is equal to $\eta$.

\section{Productivity and yield factors}

$\mathrm{R}_{\mathrm{x}}$, the productivity of biomass $(\mathrm{g} /[\mathrm{L} \cdot \mathrm{d}])$, and $\mathrm{R}_{\mathrm{E}}$, the productivity of laccase $(\mathrm{U} /[\mathrm{L} \cdot \mathrm{d}])$, can be obtained by means of Eq. (16).

$$
R_{\mathrm{E}}=\frac{1}{V_{\mathrm{f}}}\left(\frac{E_{\mathrm{f}} V_{\mathrm{f}}-E_{0} V_{0}}{t_{\mathrm{f}}-t_{0}}\right)
$$

Because $V_{\mathrm{f}}=V_{0}$ in the experiment, Eq. (16a) can be turned into (16b).

$$
R_{\mathrm{E}}=\frac{E_{\mathrm{f}}-E_{0}}{t_{\mathrm{f}}-t_{0}}
$$


Where $\mathrm{x}_{\mathrm{f}}$ is the final biomass concentration $(\mathrm{g} / \mathrm{L}), \mathrm{V}_{\mathrm{f}}$ is the final fermentation volume in a flask $(\mathrm{L}), \mathrm{t}_{\mathrm{f}}$ is the final fermentation duration, $\mathrm{E}_{\mathrm{f}}$ is the final laccase activity $(\mathrm{U} / \mathrm{ml}), \mathrm{Y}_{\mathrm{XG}}$ denotes the biomass yield on glucose $(\mathrm{g} / \mathrm{g}), \mathrm{Y}_{\mathrm{EG}}$ represents the laccase yield on glucose $(\mathrm{U} / \mathrm{g})$, and $\mathrm{Y}_{\mathrm{Ex}}$ is the biomass-specific yield of laccase (U/g). These parameters were calculated as follows:

$$
Y_{\mathrm{EG}}=\frac{E_{\mathrm{f}}-E_{0}}{G_{0}-G_{\mathrm{f}}} Y_{\mathrm{Ex}}=\frac{E_{\mathrm{f}}-E_{0}}{x_{\mathrm{f}}-x_{0}} \sqrt{a^{2}+b^{2}}
$$

Where $G_{f}$ is the final glucose concentration $(\mathrm{g} / \mathrm{L}), \mathrm{G}_{0}$ is the initial glucose concentration $(\mathrm{g} / \mathrm{L})$, and $\mathrm{x}_{0}$ was calculated by the method mentioned above. Parameters $\mathrm{x}_{\mathrm{f}}, \mathrm{E}_{\mathrm{f}}, \mathrm{E}_{0}, \mathrm{G}_{\mathrm{f}}$, and $\mathrm{G}_{0}$ were obtained from experimental data.

\section{Results and Discussion}

\section{Optimization of laccase production using agroindustrial waste}

The types of agroindustrial waste used in the experiment included tea, peanut shells, orange peel, corn cob, and bagasse. The improvement of laccase production by agroindustrial waste is shown in Fig. 1. The laccase production of all cultures with agroindustrial substrates was improved except for the culture with peanut shells. The culture with orange peel showed the maximal laccase activity: 9-fold higher than the control, whereas cultures with tea, bagasse, and corn cobs showed 5-fold, 2-fold, and 1.1-fold higher activity than the control did, respectively. Arora and Gill (2000) found that the basal media of mineral salts broth with sugarcane bagasse result in the highest enzymatic activities: 84-fold higher than those achieved in control cultures. Lorenzo et al. (2002) added agroindustrial waste to basal media and showed that barley bran is the best inducer of laccase activity, which improved the enzyme production in Paralepetopsis floridensis up to 11-fold, whereas grape stalk and grape seed yielded 6- and 4-fold increases, respectively.

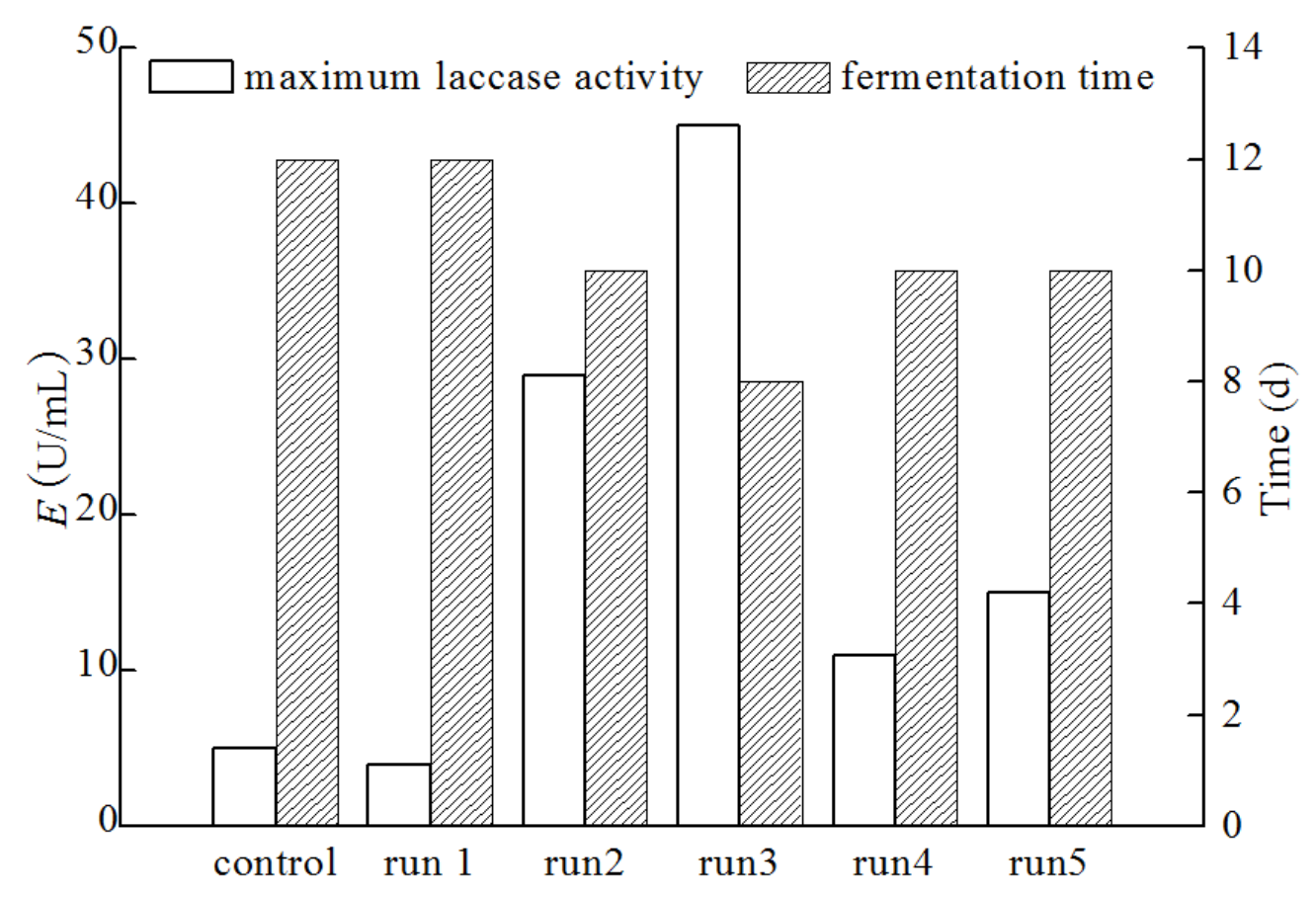

Fig. 1 - Laccase activity and fermentation time of cultures with agro-industrial wastes. Run1-5 was cultures added with peanut shell, tea, orange peel, corn cob and bagasse, respectively. 
The fermentation duration (referring to the fermentation time point when the increasing speed of laccase production begins to slow down) of all cultures with agroindustrial waste was cut short except for the culture with peanut shells. The fermentation duration was most shortened in the culture with orange peel, where the duration was reduced by $1 / 3$. The agroindustrial waste products (tea, orange peel, corn cob, and bagasse) can thus be used for optimizing laccase production. Orange peel is the best inducer because it can sharply increase laccase activity and shorten the fermentation duration substantially.

Nevertheless, when turning the liquid medium into potato extract medium (potato extract, 200 $\mathrm{g} / \mathrm{L}$; glucose, $20 \mathrm{~g} / \mathrm{L}$ ), the best inducer of laccase was peanut shells rather than orange peel (data is not shown). Parenti et al. (2013) observed the largest increase, reaching $600 \mathrm{U} / \mathrm{L}$, in shaking cultures of $P$. ostreatus N001 in the culture medium of SMY $(10 \mathrm{~g} / \mathrm{L}$ sucrose, $10 \mathrm{~g} / \mathrm{L}$ malt extract, and $4 \mathrm{~g} / \mathrm{L}$ yeast extract) using wheat straw extract. On the other hand, there was little laccase induction in the minimal M7GY medium (10 g/L glucose, $2 \mathrm{~g} / \mathrm{L}$ ammonium tartrate, $0.5 \mathrm{~g} / \mathrm{L} \mathrm{MgSO} \cdot 7 \mathrm{H}_{2} \mathrm{O}, 1 \mathrm{~g} / \mathrm{L}$ $\mathrm{KH}_{2} \mathrm{PO}_{4}, 0.5 \mathrm{~g} / \mathrm{L} \mathrm{KCl}, 1 \mathrm{~g} / \mathrm{L}$ yeast extract, and $1 \mathrm{~mL} / \mathrm{L}$ of a solution of trace elements). These results suggest that different strains have their own optimal substrates, and that the inducer effect varies with the culture medium and growth conditions (Lorenzo et al. 2002).

\section{Kinetic models}

The process of computation of the kinetic models for the culture under control conditions is shown below.

\section{The model of fungal growth kinetics}

Initially, the biomass entered a lag phase followed by an exponential growth phase in the growth curve. The biomass concentration and laccase activity increased simultaneously when the fungi entered the exponential phase. Assuming that $\mathrm{x}_{\max }=0.60 \mathrm{~g} / \mathrm{L}$, a plot of Eq. (1) yielded $\mu_{\mathrm{m}}=0.42 / \mathrm{d}$, corresponding to $\mathrm{x}_{0}=0.0153 \mathrm{~g} / \mathrm{L}$ (Fig. 2).

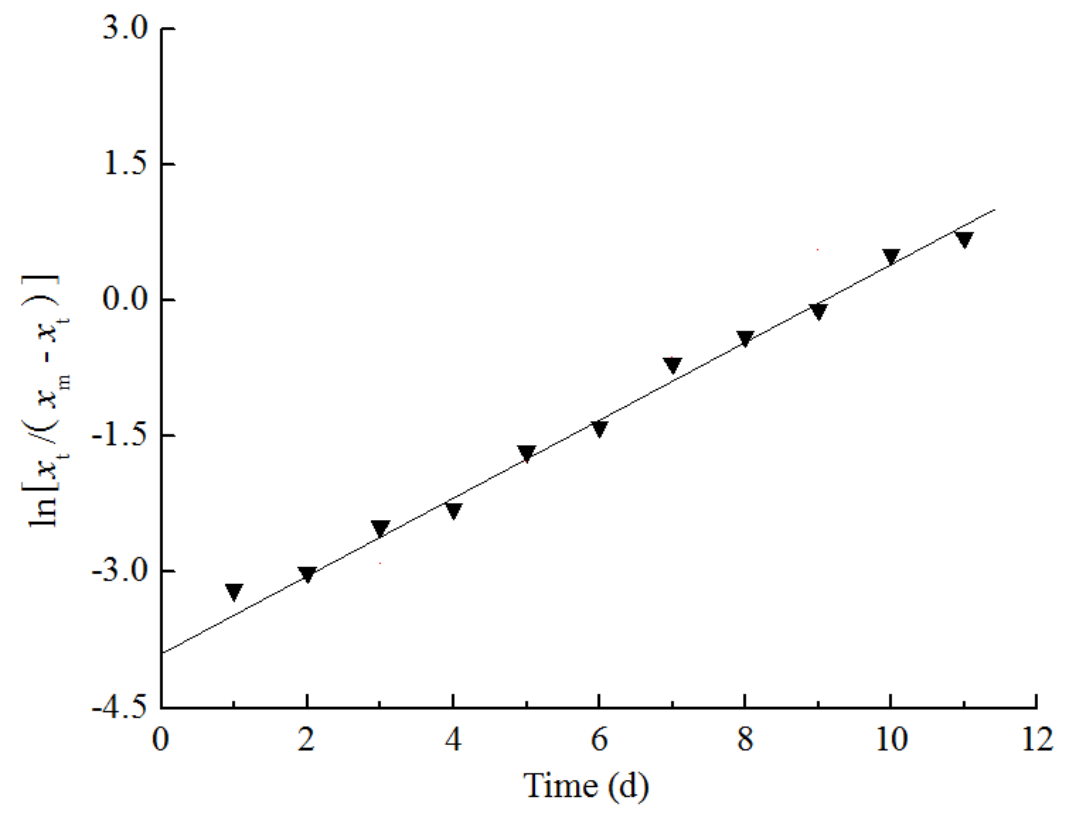

Fig. 2 - Evaluation of $x_{0}$ and $\mu_{m}$. (Filled triangle was the experimental value of $\ln \left[\mathrm{x}_{\mathrm{t}} /\left(\mathrm{x}_{\max }-\mathrm{x}_{\mathrm{t}}\right)\right]$ at certain day. Points on the line were the fitted value of $\ln \left[\mathrm{x}_{\mathrm{t}} /\left(\mathrm{x}_{\max }-\mathrm{x}_{\mathrm{t}}\right)\right]$ at certain time. The slope of the line was the $\mu_{\mathrm{m}}(/ \mathrm{d})$, maximum specific growth rate. The $\mathrm{y}$ intercept was equal to $-\ln \left[\left(\mathrm{x}_{\max } / \mathrm{x}_{0}\right)-1\right]$. $\left.\mathrm{x}_{\max }=0.60 \mathrm{~g} / \mathrm{L}\right)$. 


\section{The kinetic model of Laccase formation}

Laccase formation parameters were determined; $\mu_{\mathrm{m}}, \mathrm{x}_{\max }$, and $\mathrm{x}_{0}$ were calculated above. $\beta=\frac{d E / d t}{x_{\max }}=0.952 U / g / d$

The slope of the line in Fig. 3 indicates that $\alpha=4.988 \mathrm{U} / \mathrm{g}$.

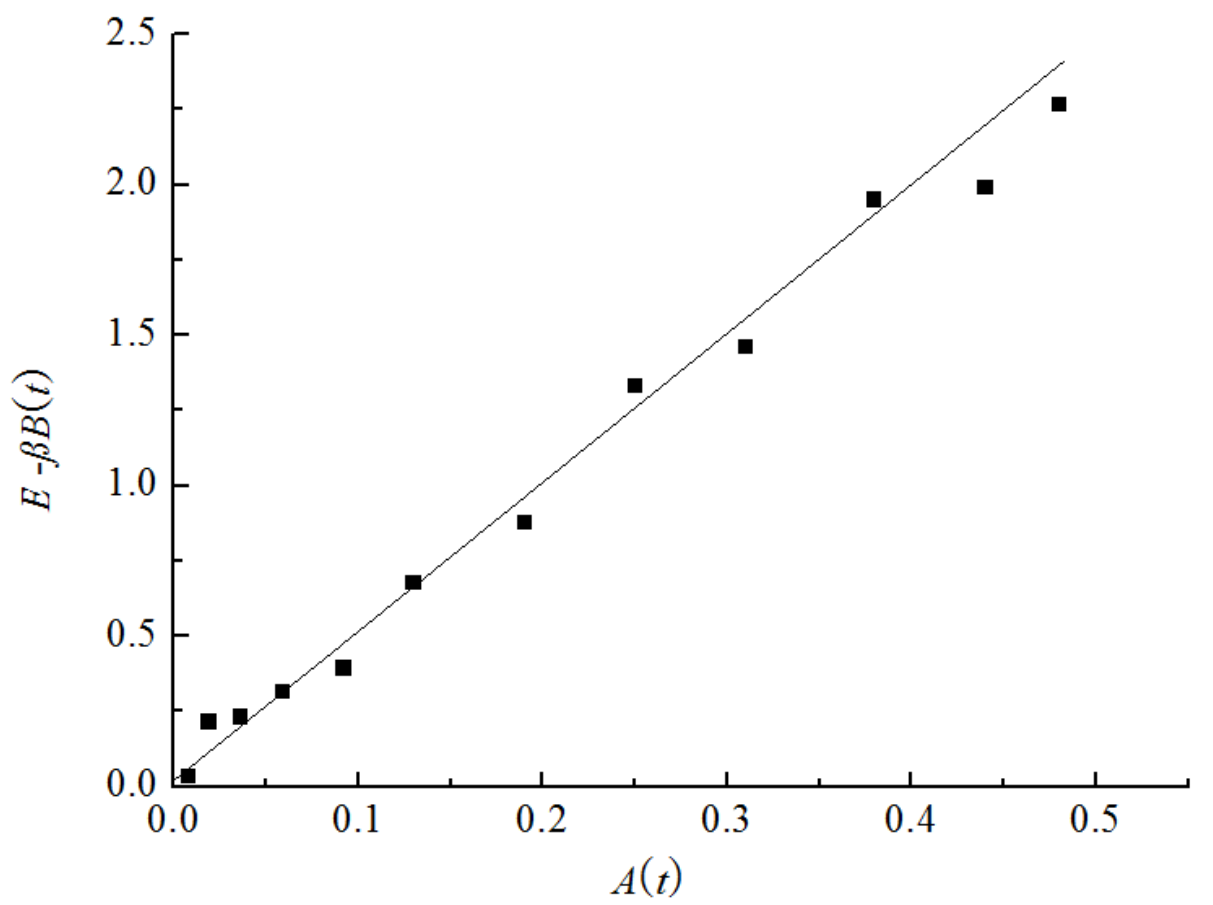

Fig. 3 - Determination of $\alpha$. (Filledrectangle was the experimental value of $E-\beta B(t)$ at certain day. The slope of the line was the $\alpha(\mathrm{U} / \mathrm{g})$, growth associated constant for laccase formation. $\beta$, the biomass associated constant for laccase formation, was equal to $0.952 \mathrm{U} / \mathrm{g} / \mathrm{d}$ ).

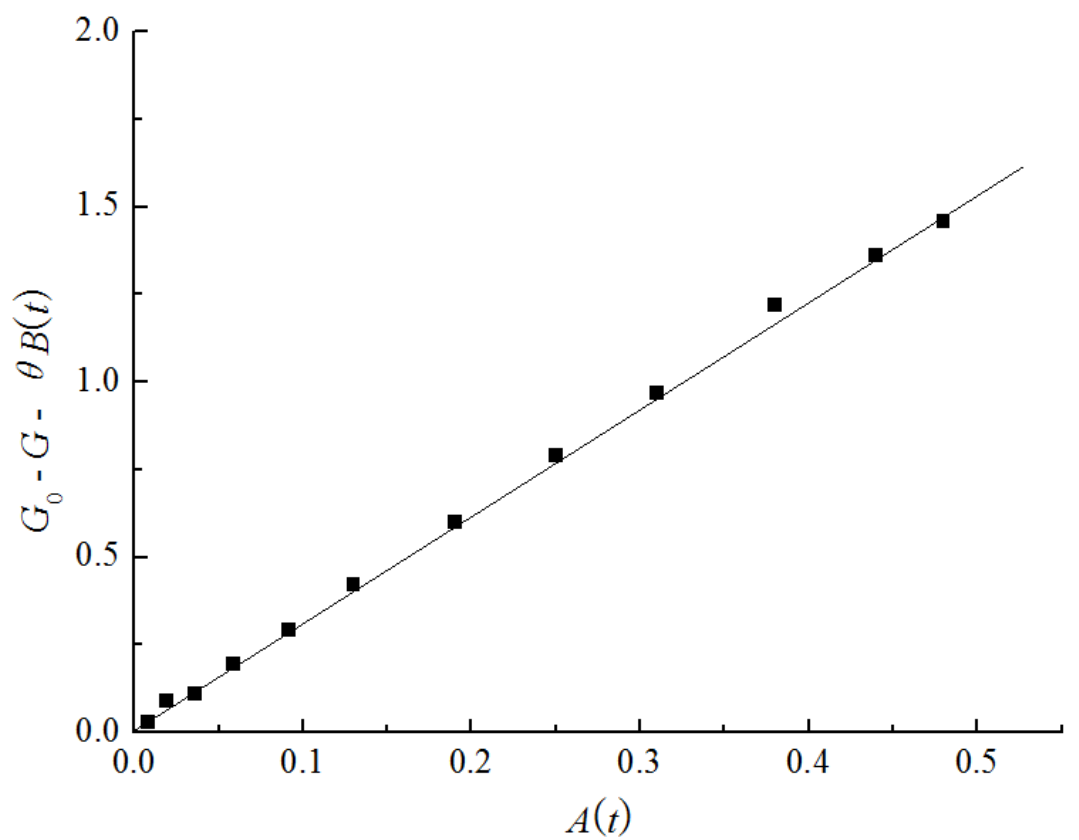

Fig. 4 - Evaluation of $\eta$. (Filled rectangle was the experimental value of $G_{0}-G-\theta B(t)$ at certain day. The slope of the line was the $\eta$, which was equal to $1 / \mathrm{Y}_{\mathrm{X} / \mathrm{G}} . \theta$ was the fungi maintenance coefficient on glucose. $\mathrm{G}_{0}$ was the initial glucose concentration, which was equal to $5 \mathrm{~g} / \mathrm{L}$. 


\section{The kinetic model of glucose consumption}

The decrease in residual glucose concentration was accompanied by an increase in biomass concentration during laccase formation. The parameter $\theta$ can be determined by means of Eq. (13):

$$
\theta=-\frac{d G / d t}{x_{\max }}=0.64 \mathrm{~g} / \mathrm{g} / \mathrm{d}
$$

The initial glucose concentration was $\mathrm{G}_{0}=5 \mathrm{~g} / \mathrm{L}$. A plot of Eq. (15) is shown in Fig. 4 and provided a slope of $\eta=3.15 \mathrm{~g} / \mathrm{g}$.

\section{Verifying the models}

The biomass concentration (x), laccase activity (E), and glucose concentration (G) were calculated by means of Eqs. (1), (9), and (14), respectively, using the kinetic parameters determined above. Experimental data are compared with simulation data in Fig. 5. The average error of simulation data and experimental data was less than $5 \%$. The model appeared to provide a reasonable description for the dynamic characteristics of the fermentation process. A summary of these parameters in control culture is shown in Table 1. One of the major limitations of the model is that the model agrees well with the experimental data during the growth phase, but not the stationary phase and decline phase.

\section{Effects of the factors on fermentation kinetics}

The effects of factors (agroindustrial waste, copper induction, and agitation) on the fermentation kinetics were evaluated by the method of OFAT (vary only one factor at a time while keeping the others fixed) and the results are summarized in Table 2.

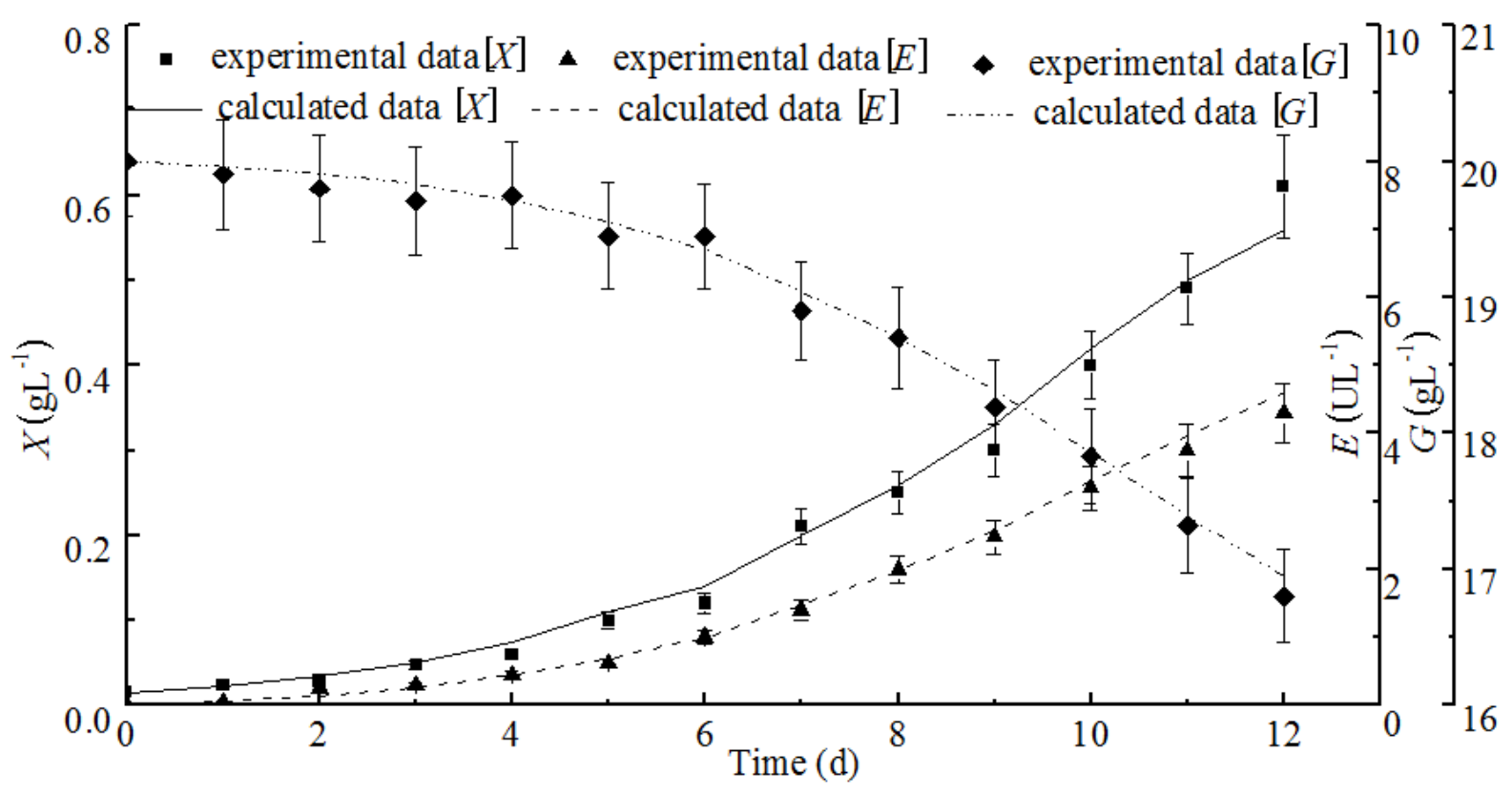

Fig. 5 - Comparison of calculated data and experimental data. (x, E, G were the biomass concentration, laccase activity and the glucose concentration, respectively. The filled triangle and rectangle were the experimental data. The three curves were the calculated data of the kinetics models. The average error of simulation data and experimental data was less than 5\%). 
Table 1 Kinetic parameters for the culture of control

\begin{tabular}{lc}
\hline Parameter & Calculated value \\
\hline$x_{0}, \mathrm{~g} / \mathrm{L}$ & $0.015 \pm 0.012$ \\
$x_{\mathrm{m}}, \mathrm{g} / \mathrm{L}$ & $0.60 \pm 0.12$ \\
$\mu_{\mathrm{m}}, / \mathrm{d}$ & $0.42 \pm 0.08$ \\
$\alpha, \mathrm{U} / \mathrm{g}$ & $4.99 \pm 0.50$ \\
$\beta, \mathrm{U} / \mathrm{mL} / \mathrm{d}$ & $0.95 \pm 0.20$ \\
$\theta, \mathrm{g} / \mathrm{g} / \mathrm{d}$ & $3.97 \pm 0.80$ \\
$\eta, \mathrm{g} / \mathrm{g}$ & $18.92 \pm 3.78$ \\
$r_{\mathrm{x}}, \mathrm{g} / \mathrm{L} / \mathrm{d}$ & $0.051 \pm 0.01$ \\
$r_{\mathrm{p}}, \mathrm{U} / \mathrm{mL} / \mathrm{d}$ & $0.36 \pm 0.07$ \\
$Y_{\mathrm{xs}}, \mathrm{g} / \mathrm{g}$ & $0.20 \pm 0.09$ \\
$Y_{\mathrm{ps}}, \mathrm{U} / \mathrm{g}$ & $1667 \pm 700$ \\
$Y_{\mathrm{px}}, \mathrm{U} / \mathrm{g}$ & $8333 \pm 1500$ \\
\hline
\end{tabular}

Table 2 The effects of three factors on fermentation kinetic characterization

\begin{tabular}{llccccccc}
\hline Run & Variation & & $\boldsymbol{\mu}_{\mathbf{m}}(\mathbf{/ d})$ & $\boldsymbol{A}(\mathbf{U} / \mathbf{g})$ & $\begin{array}{c}\boldsymbol{B} \\
(\mathbf{U} / \mathbf{m L} / \mathbf{d})\end{array}$ & $\begin{array}{c}\boldsymbol{R}_{\mathbf{E}} \\
(\mathbf{U} / \mathbf{m L} / \mathbf{d})\end{array}$ & $\boldsymbol{Y}_{\mathbf{E G}}(\mathbf{U} / \mathbf{g}) \times \mathbf{1 0}^{3}$ & $\boldsymbol{Y}_{\mathbf{E x}}(\mathbf{U} / \mathbf{g}) \times \mathbf{1 0}^{\mathbf{3}}$ \\
\hline 0 & non & & $0.42 \pm 0.08$ & $4.99 \pm 0.50$ & $0.95 \pm 0.20$ & $0.36 \pm 0.10$ & $1.67 \pm 0.7$ & $8.33 \pm 1.5$ \\
A1 & Orange peel & 5 & $0.50 \pm 0.08$ & $8.20 \pm 1.03$ & $2.50 \pm 0.30$ & $1.33 \pm 0.17$ & $3.81 \pm 1.2$ & $20.0 \pm 5.4$ \\
A2 & (g/L) & 10 & $0.61 \pm 0.10$ & $10.51 \pm 1.26$ & $3.76 \pm 0.70$ & $3.75 \pm 0.42$ & $6.75 \pm 0.9$ & $26.3 \pm 6.6$ \\
A3 & & 20 & $0.64 \pm 0.10$ & $9.8 \pm 1.10$ & $3.90 \pm 0.40$ & $3.92 \pm 0.25$ & $6.71 \pm 1.0$ & $26.1 \pm 5.1$ \\
B1 & Copper (mM) & 0.1 & $0.41 \pm 0.08$ & $6.01 \pm 0.80$ & $4.26 \pm 0.80$ & $0.93 \pm 0.09$ & $3.61 \pm 1.1$ & $19.3 \pm 7.8$ \\
B2 & & 1 & $0.42 \pm 0.08$ & $10.3 \pm 1.20$ & $11.6 \pm 1.30$ & $2.46 \pm 0.13$ & $8.94 \pm 2.1$ & $47.6 \pm 15.7$ \\
B3 & & 2 & $0.39 \pm 0.08$ & $8.7 \pm 1.05$ & $6.92 \pm 0.85$ & $1.53 \pm 0.08$ & $6.54 \pm 1.9$ & $32.7 \pm 13.3$ \\
C1 & Agitation (rpm) & 100 & $0.37 \pm 0.07$ & $4.03 \pm 0.80$ & $0.90 \pm 0.18$ & $0.21 \pm 0.04$ & $2.06 \pm 1.2$ & $8.23 \pm 4.2$ \\
C2 & & 200 & $0.49 \pm 0.10$ & $5.20 \pm 0.70$ & $0.93 \pm 0.12$ & $0.55 \pm 0.10$ & $1.33 \pm 0.4$ & $8.42 \pm 2.96$ \\
C3 & & 250 & $0.30 \pm 0.07$ & $4.00 \pm 0.78$ & $0.75 \pm 0.13$ & $0.12 \pm 0.03$ & $1.00 \pm 0.8$ & $5.32 \pm 2.46$ \\
\hline
\end{tabular}

\section{Effects of adding agroindustrial waste on fermentation kinetics}

Compared with the control culture, $\mu_{\mathrm{m}}, \alpha$, and $\beta$ were enhanced by orange peel extract; this finding means that orange peel promoted the proliferation capacity of the fungi and their laccase-producing ability. The maximal $\mu_{\mathrm{m}}$ of the culture with orange peel extract was 1.5 -fold greater than that of the control, and the generation time was shortened by $1 / 3$. In other words, the proliferation capacity of the culture with orange peel extract was 0.5 -fold higher than that of control. Increasing $\alpha$ and $\beta$ (enhancement of laccase production with per gram dry weight biomass per day) means improvement in the ability of the fungi to produce laccase, which can also be found by the increasing $\mathrm{Y}_{\mathrm{EX}}$. The rate of laccase production and laccase production with per gram of glucose are $\mathrm{r}_{\mathrm{E}}$ and $\mathrm{Y}_{\mathrm{ES}}$, respectively. These parameters increase simultaneously implying that they need less time and glucose than before to produce the same amount of laccase. Thus, more laccase can be obtained with the same amount of time and glucose.

Parameters $\mu, \alpha, \beta, \mathrm{Y}_{\mathrm{EX}}, \mathrm{r}_{\mathrm{E}}$, and $\mathrm{Y}_{\mathrm{ES}}$ were improved by an increase in the supplementation with orange peel, which ranged from 0 to $10 \mathrm{~g} / \mathrm{L}$. That is to say, the more orange peel was added to the culture, the better was the optimization. This observation is consistent with the results of Elisashvili et al. (2006). Furthermore, $\mu, \alpha, \beta, Y_{E X}, r_{E}$, and $Y_{E S}$ hardly changed when the amount of orange peel surpassed $10 \mathrm{~g} / \mathrm{L}$. In contrast, parameters $\mu, \alpha, \beta, \mathrm{Y}_{\mathrm{EX}}, \mathrm{R}_{\mathrm{E}}$, and $\mathrm{Y}_{\mathrm{ES}}$ decreased with the increasing 
amount when the addition of orange peel exceeded the optimal value. The difference may result from the switch from orange peel to orange peel extracts.

In accordance with Eq. (8), laccase formation is determined by $\alpha, \beta, \mathrm{x}(\mathrm{t})$, and biomass growth. The biomass concentration $\mathrm{x}(\mathrm{t})$ and biomass growth rely on $\mu$ when $\mathrm{x}_{0}$ is fixed. Therefore, the increase in $\alpha, \beta$, and $\mu$ should result in production of more laccase. According to Table 2 , the enhancement of laccase production was caused by increased $\alpha, \beta$, and $\mu$. In shaking cultures of SMY, the biomass evolution and residual glucose concentration of the culture with wheat straw extracts barely changed as compared to the culture without wheat straw extracts; the reason for the enhancement of laccase activity was an increase in $\alpha$ and/or $\beta$ (Parenti et al. 2013). The varying conclusions may be due to differences in the composition of the two substrates.

\section{Effects of copper induction on fermentation kinetics}

The maximal laccase activity $\left(\mathrm{E}_{\max }\right)$ was different in the range of $0-2 \mathrm{mM}$ copper, and the highest activity was obtained at $1 \mathrm{mM}$ copper. Judging by Table 2, one can see that improvement of $\alpha, \beta, r_{E}, Y_{E X}$, and $Y_{E S}$ showed a positive correlation with the increasing copper supplementation (when the copper concentration was less than $1 \mathrm{mM}$ ) and a negative correlation (when copper concentration was more than $1 \mathrm{mM}$ ). Although there was a negative correlation when the copper concentration exceeded $1 \mathrm{mM}$, copper played a major role in inducing laccase formation. When the copper concentration is below the optimal one, laccase production improves with the increase in copper supplementation, but when the copper concentration is above the optimal concentration, the laccase production improves with a decrease in copper supplementation (Hess et al. 2002, Saparrat 2004, Tavares et al. 2005). The optimal copper concentration varies among fungal strains because of differences in sensitivity to copper (Palmieri et al. 2000, Levin et al. 2002, Saparrat 2004, Tavares et al. 2005). Biomass growth is not affected by the presence of copper because the biomass growth curve is almost the same with or without copper (Palmieri et al. 2000). Here, when the copper concentration changed from 0 to $2 \mathrm{mM}, \mu$ and $x_{\max }$ were almost not affected.

Thus, parameters $\mu$ and $\alpha$ have nothing to do with copper, whereas the increase in $\beta$ accounts for the improvement of laccase activity when copper is used for laccase production (Tinoco-Valencia et al. 2014). Maximal laccase activity depends on the biomass produced and the growth-associated and growth-independent constants (Tinoco-Valencia et al. 2014). High copper content of the liquid culture will inhibit fungal growth to a certain extent, but it can still promote laccase formation. It is clear that fungal proliferation capacity $(\mu)$ and the laccase-producing ability of the fungi ( $\alpha$ and/or $\beta$ ) were affected by high copper concentration in an opposite manner. Nonetheless, the stimulatory effects were stronger than the inhibitory effects. From these results, we infer that the reason for laccase upregulation with copper induction is the improvement of laccase-producing ability of the fungi (the increase in $\alpha$ and/or $\beta$ ). In contrast, excessive copper is toxic and inhibits biomass growth; the latter change will cause morphological and physiological changes and will affect the proliferation capacity of the fungi and enzyme formation (Baldrian 2003).

\section{Effects of agitation rate on fermentation kinetics}

Table 2 shows a positive correlation between an increase in $\mu$ and an increase in the rotation rate. On the other hand, the positive correlation turned into a negative one when the rotation rate surpassed $200 \mathrm{rpm}$. The enzymatic activity and $\mu$ attained their maxima $(\sim 6.65 \mathrm{U} / \mathrm{mL}$ and $0.49 / \mathrm{d}$, respectively) at an agitation rate of $200 \mathrm{rpm}$. Higher speeds of agitation can cause higher energy and oxygen transfer to the fungal culture (Buchs 2001). As a result, fungal growth will be promoted with increasing agitation, but only up to a certain point (Saat et al. 2014). If the agitation rate were beyond 
the optimal rate, then fungal growth would be inhibited because of the sensitivity of biomass to the excessive mixing and hydrodynamic shear stress (Abd-Aziz et al. 2008). Increasing the agitation rate appropriately can be beneficial for laccase production because higher $\mu$ will promote enzyme formation.

As shown in Table 2, the values of $\alpha$ and $\beta$ hardly changed with the increasing agitation rate. Nevertheless, excessive agitation rate will lower $\alpha$ and $\beta$. The values of $\alpha$ and $\beta$ are not significantly influenced by the agitation rate for laccase production associated with no growth (Saat et al. 2014). It is generally accepted that high agitation rates are detrimental for enzyme production by white-rot fungi because excessive agitation tends to cause deactivation or proteolysis of enzymes (Moreira et al. 1998, Birhanli \& Yesilada 2010, Tinoco-Valencia et al. 2014). Parameters $\alpha$ and $\beta$ can be negative, zero, or positive (Tinoco-Valencia et al. 2014). Apparently, excessive agitation rates should not be used because of their inhibitory effects on the enzyme production manifesting themselves as a decline of $\alpha, \beta$, and $\mu$. Tavares et al. (2006) found that the agitation rate does not play an important role in laccase production. The reason for the opposite conclusion may be that the optimal agitation rate was near and between the speeds selected (100 and $180 \mathrm{rpm})$ in the experiment, and the results of the joint effects of the two different agitation rates on proliferation capacity $(\mu)$ and the ability of the fungi to produce laccase ( $\alpha$ and/or $\beta$ ) are the same. It can thus be deduced that the major reason for the enhancement was an increase in proliferation capacity $(\mu)$.

At an agitation rate of $200 \mathrm{rpm}, \mathrm{Y}_{\mathrm{ES}}$ was smaller than that of control. Meanwhile, $\mathrm{R}_{\mathrm{E}}$ was 2-fold lower than that in the control. This means that it takes less time to obtain the same quantity of laccase but more glucose is needed. From the standpoint of the utilization rate of glucose, this approach is not economical for laccase production.

When the agitation rate was less than optimal, the effects of increasing agitation rate on $\mu$ were stronger than those on $\alpha$ and/or $\beta$. Excessive agitation leads to a decrease in $\mu, \alpha$, and $\beta$. Consequently, $\mathrm{E}_{\max }$ was first improved by the increasing agitation rate and then was reduced by an excessive agitation rate.

\section{Conclusion}

Agroindustrial waste products such as tea, orange peel, corn cob, and bagasse can be used as natural substrates for laccase production. The maximal laccase activity ( $45 \mathrm{U} / \mathrm{mL}$ ) of cultures with orange peel was 9-fold higher than that in the control, and the fermentation duration was shortened from 12 to 8 days. These data show that orange peel is the best substrate for laccase production. The orange peel extract not only greatly improved the fungal ability to proliferate and to produce laccase but also increased the productivity and yield factors in comparison with the control. Lignin, cellulose, hemicellulose, and other components of orange peel can serve as carbon sources for fungal growth (Stajic et al. 2006). Moreover, some natural inducers in the waste can promote laccase production efficiently. Many studies are focused on improving laccase production by changing culture conditions or by adding inducers, but the research on the reasons for the enhancement of laccase production is scarce. The established kinetic models were used to analyze the influences of three factors (addition of agroindustrial waste, copper induction, and stronger agitation) on the fermentation kinetics and to discuss the reasons for the enhancement of laccase production in terms of laccase fermentation kinetics. The reason for the enhancement of laccase production after addition of orange peel extract was the augmentation of $\alpha, \beta$ and $\mu$; the reason for enhancement after supplementation with copper was an increase in $\alpha$ and/or $\beta$; the reason for enhancement of laccase production by regulation of the rotation rate was mainly the enhancement of $\mu$. The optimization results on laccase production were usually quantified with respect to the maximal 
laccase activity or fermentation duration. The results of optimization could be assessed by means of the kinetic parameters, aside from assessing maximal laccase activity and fermentation duration. These parameters are conducive to a better understanding of the fermentation process and can serve as a reference for enhancement of enzyme production.

\section{Acknowledgements}

This work was financed by National Natural Science Foundation of China (No.51408290), Natural Science Foundation of Liaoning Province, China (No.2014020112) and the Doctoral Scientific Research Foundation of Liaoning Province, China (No.20131046).

\section{Conflicts of interest}

All of the authors declare that they have no conflicts of interest regarding this paper.

\section{References}

Abd-Aziz S, Fernandez CC, Salleh MM, Illias RM, Hassan MA. 2008 - Effect of agitation and aeration rates on chitinase production using Trichoderma virens UKM1 in 2-1 stirred tank reactor. Applied Biochemistry and Biotechnology 150, 193-204.

Akpinar M, Urek RO. 2014 - Extracellular ligninolytic enzymes production by Pleurotus eryngii on agroindustrial wastes. Preparative Biochemistry \& Biotechnology 44, 772-781.

Arora DS, Gill PK. 2000 - Laccase production by some white rot fungi under different nutritional conditions. Bioresource Technology 73, 283-285.

Asadgol Z, Forootanfar H, Rezaei S, Mahvi AH, Faramarzi MA. 2014 - Removal of phenol and bisphenol-A catalyzed by laccase in aqueous solution. Journal of Environmental Health Science and Engineering 12, 93-97.

Baldrian P. 2003 - Interactions of heavy metals with white-rot fungi. Enzyme and Microbial Technology 32, 78-91.

Baldrian P. 2006 Fungal laccases-occurrence and properties. Fems Microbiology Reviews 30, $215-242$.

Bankar SB, Singhal RS. 2012 - Fermentation kinetics makeover in poly- $\varepsilon$-lysine biosynthesis by Stueptomyces noursei NRRL 5126. Journal of Biochemical Technology 3, 312-316.

Bettin F, Montanari Q, Calloni R, Gaio TA, Silveira MM, Dillon AJP. 2014 - Additive effects of $\mathrm{CuSO}_{4}$ and aromatic compounds on laccase production by Pleurotus sajor-caju PS-2001 using sucrose. Brazilian Journal of Chemical Engineering 31, 335-346.

Birhanli E, Yesilada O. 2010 - Enhanced production of laccase in repeated-batch cultures of Funalia trogii and Trametes versicolor. Biochemical Engineering Journal 52, 33-37.

Buchs J. 2001 - Introduction to advantages and problems of shaken cultures. Biochemical Engineering Journal 7, 91-98.

Chairin T, Nitheranont T, Watanabe A, Asada Y, Khanongnuch C, Lumyong S. 2013 Biodegradation of bisphenol A and decolorization of synthetic dyes by laccase from white-rot fungus, Trametes polyzona. Applied Biochemistry and Biotechnology 169, 539-545.

Elibol M, Mavituna F. 1999 - A kinetic model for actinorhodin production by Streptomyces coelicolor A3(2). Process Biochemistry 34, 625-631.

Elisashvili V, Penninckx M, Kachlishvili E, Asatiani M, Kvesitadze G. 2006 - Use of Pleurotus dryinus for lignocellulolytic enzymes production in submerged fermentation of mandarin peels and tree leaves. Enzyme and Microbial Technology 38, 998-1004. 
Elisashvili V, Penninckx M, Kachlishvili E, Tsiklauri N, Metreveli E, Kharziani T, Kvesitadze G. 2008 - Lentinus edodes and Pleurotus species lignocellulolytic enzymes activity in submerged and solid-state fermentation of lignocellulosic wastes of different composition. Bioresource Technology 99, 457-462.

Gassara F, Brar SK, Tyagi RD, John RP, Verma M, Valero JR. 2011 - Parameter optimization for production of ligninolytic enzymes using agro-industrial wastes by response surface method. Biotechnology and Bioprocess Engineering 16, 343-351.

Giardina P, Palmieri G, Fontanella B, Rivieccio V, Sannia G. 2000 - Manganese peroxidase isoenzymes produced by Pleurotus ostreatusgrown on wood sawdust. Archives of Biochemistry and Biophysics 376, 171-179.

Gonzalez JC, Medina SC, Rodriguez A, Osma JF, Alméciga-Díaz CJ, Sánchez OF.2013 Production of Trametes pubescenslaccase under submerged and semi-solid culture conditions on agro-industrial wastes. Plos One 8, e73721.

Hess J, Leitner C, Galhaup C, Kulbe KD, Hinterstoisser B, Steinwender M, Haltrich D. 2002 Enhanced formation of extracellular laccase activity by the white-rot fungus Trameles mullicolor. Applied Biochemistry and Biotechnology 98-100, 229-241.

Levin L, Forchiassin F, Ramos AM.2002 - Copper induction oflignin-modifying enzymes in the white-rot fungus Trametes trogii. Mycologia 94, 377-383.

Li Q, Pei J, Zhao L, Xie J, Cao F, Wang G. 2014 Overexpression and characterization of laccase from Trametes versicolor in Pichia pastoris. Applied Biochemistry and Microbiology 50, 140-147.

Lorenzo M, Moldes D, Rodríguez Couto S, Sanroman A. 2002- Improving laccase production by employing different lignocellulosic wastes in submerged cultures of Trametes versicolor. Bioresource Technology 82, 109-113.

Miller GL. 1959 - Use of dinitrosalicylic acid reagent for determination of reducing sugar. Analytical Chemistry 31, 426-428.

Minussi RC, Pastore GM, Duran N. 2007 - Laccase induction in fungi and laccase/N-OH mediator systems applied in paper mill effluent. Bioresource Technology 98, 158-164.

Mohajershojaei K, Mahmoodi NM, Khosravi A. 2015 - Immobilization of laccase enzyme onto titania nanoparticle and decolorization of dyes from single and binary systems. Biotechnology and Bioprocess Engineering 20, 109-116.

Moreira MT, Palma C, Feijoo G, Lema JM. 1998 - Strategies for the continuous production of ligninolytic enzymes in fixed and fluidised bed bioreactors. Journal of Biotechnology 66, 27-39.

Mussatto SI. 2009 - Biotechnological potential of brewing industry by-products. In: Nigam PS and Pandey A (eds.). Biotechnology for Agro-Industrial Residues Utilisation. Springer Netherlands, 313-326.

Palmieri G, Giardina P, Bianco C, Fontanella B, Sannia G.2000 - Copper induction of laccase isoenzymes in the ligninolyticfungus Pleurotus ostreatus. Applied and Environmental Microbiology 66, 920-924.

Parenti A, Muguerza E, Iroz AR, Omarini A, Conde E, Alfaro M, Castanera R, Santoyo F, Ramírez L, Pisabarro AG.2013 - Induction of laccase activity in the white rot fungus Pleurotus ostreatususing water polluted with wheat straw extracts. Bioresource Technology 133, 142-149.

Reddy GV, Babu PR, Komaraiah P, Roy KR, Kothari IL. 2003 - Utilization of banana waste for the production of lignolytic and cellulolytic enzymes by solid substrate fermentation using two 
Pleurotus species (P. ostreatus and P. sajor-caju). Process Biochemistry 38, 1457-1462.

Saat MN, Annuar MS, Alias Z, Chuan LT, Chisti Y. 2014 - Modeling of growth and laccase production by Pycnoporus sanguineus. Bioprocess and Biosystems Engineering 37, 765-775.

Saparrat MCN. 2004 - Optimizing production of extracellular laccase from Grammothele subargenteaCLPS No.436 strain. World Journal of Microbiology \& Biotechnology 20, 583-586.

Sathishkumar P, Palvannan T, Murugesan K, Kamala-Kannan S. 2013 - Detoxification of malachite green by Pleurotus florida laccase produced under solid-state fermentation using agricultural residues. Environmental Technology 34, 139-147.

Seyis I, Aksoz N. 2005 - Xylanase production from Trichoderma harzianum 1073 D3 with alternative carbon and nitrogen sources. Food Technology and Biotechnology 43, 37-40.

Singh Arora D, Kumar Sharma R. 2010 - Ligninolytic fungal laccases and their biotechnological applications. Applied Biochemistry and Biotechnology 160, 1760-1788.

Sondhi S, Sharma P, George N, Chauhan SP, Pun N, Gupta N. 2015 - An extracellular thermo-alkali-stable laccase from Bacillus tequilensis SN4, with a potential to biobleach softwood pulp. Biotechnology 5, 1-11.

Stajic M, Persky L, Friesem D, Hadar Y, Wasser SP, Nevo E, Vukojević J. 2006 - Effect of different carbon and nitrogen sources on laccase and peroxidases production by selected Pleurotus species. Enzyme and Microbial Technology 38, 65-73.

Tavares AP, Coelho MA, Agapito MS, Coutinho JA, Xavier AM. 2006 - Optimization and modeling of laccase production by Trametes versicolor in a bioreactor using statistical experimental design. Applied Biochemistry and Biotechnology 134, 233-248.

Tavares AP, Coelho MA, Coutinho JA, Xavier A.2005 - Laccase improvement in submerged cultivation: induced production and kinetic modelling. Journal of Chemical Technology and Biotechnology 80, 669-676.

Tinoco-Valencia R, Gómez-Cruz C, Galindo E, Serrano-Carreón L. 2014 - Toward an understanding of the effects of agitation and aeration on growth and laccases production by Pleurotus ostreatus. Journal of Biotechnology 177, 67-73.

Unal A, Çabuk A, Kolankaya N. 2011 - Dechlorination of 2,4,6-trichlorophenol by free and immobilized laccase from Trametes versicolor in a lab scale bioreactor. Anadolu University Journal of Science and Technology 1, 113-124.

Vendruscolo F, Albuquerque PM, Streit F, Esposito E, Ninow JL. 2008 - Apple pomace: A versatile substrate for biotechnological applications. Critical Reviews in Biotechnology 28, 1-12.

Zhang J, Zou FX, Yu XX, Huang X, Qu Y. 2014 - Ionic liquid improves the laccase-catalyzed synthesis of water-soluble conducting polyaniline. Colloid and Polymer Science 292, 2549-2554. 